\title{
ESTUDIOS
}

\section{La muerte como fenómeno cantado en el repertorio infantil tradicional chileno}

\author{
Death as a sung phenomenon in traditional \\ Chilean children's songs
}

\author{
por \\ Daniela Banderas Grandela \\ Departamento de Música, \\ Universidad de La Serena, Chile \\ danielabanderas@gmail.com
}

\begin{abstract}
Se constata en el cancionero tradicional infantil chileno e hispanoamericano la presencia sistemática del tópico de la muerte, cuestión que se hace especialmente evidente en antiguos romances que han sobrevivido arraigados a dicho repertorio. El presente trabajo aborda el tratamiento de esta temática en los versos de estas canciones, explorando sus contenidos arquetípicos, relacionando aspectos estrictamente musicales con aquellos referidos a los textos, e indagando en la función que estos cantos desempeñan en la maduración psíquica del niño. De esta forma se profundiza en un segmento del cancionero tradicional chileno, comprendiéndolo como portador de sentido en su dimensión simbólica y como importante fragmento de la memoria y el imaginario colectivo.
\end{abstract}

Palabras claves: Canción infantil, romance, muerte, simbolismo.

The systematic presence of the topic of death is confirmed in the traditional Chilean and Hispanic American children's songs, an issue that becomes especially evident in the ancient romances that have survived in this repertoire. The present work deals with the treatment of this subject in the verses of these songs, exploring their archetypal contents, relating strictly musical aspects with those referring to the texts, and investigating the function that these songs play in the psychic maturation of the child. In this way, a segment of the traditional Chilean songs collection is examinated, understanding it as a bearer of meaning in its symbolic dimension and as an important fragment of the collective imaginary and memory.

Keywords: Childish song, romance, death, symbolism.

\section{INTRODUCCIÓN}

La canción infantil tradicional forma parte de un valioso cúmulo de manifestaciones folclóricas (como mitos, cuentos, leyendas, juegos, refranes), y, como tales, se caracteriza por carecer de autor conocido, poseer una forma de comunicación oral, ser mestiza, aglutinante y representativa de una comunidad, y ser portadora y transmisora de conocimientos ancestrales, constituyéndose en espacio simbólico donde comparece el imaginario colectivo. Este último punto es crucial y se ancla en la premisa de que el folclore 
"es un camino que lleva a las raíces, a aquellos universos simbólicos que han acompañado a los pueblos en su historia larga. Como bagaje que el hombre ha metabolizado de generación en generación, obviamente dice algo importante acerca de su modo de existencia personal y colectiva, de su cultura y de su identidad"1.

Esta canción sigue ocupando un lugar en el quehacer infantil, mas, las transformaciones culturales y la incorporación de nuevos referentes por parte de la industria, han llevado a que la práctica de este repertorio se encuentre en un momento crítico. La aparición de agrupaciones de música infantil, que cuentan con medios de producción y difusión modernos, ha conducido al progresivo abandono de un repertorio que hasta hace unas décadas constituía el principal corpus musical practicado por los niños. Luego, las canciones que han desaparecido en mayor medida de esta praxis son aquellas que tratan temáticas actualmente consideradas poco aptas para un niño, como es el caso de la muerte. Sin embargo, si indagamos en el cancionero tradicional chileno e hispanoamericano, llama la atención la sistemática presencia de esta última.

Establecer una lectura metafórica del fenómeno "canción tradicional infantil de muerte" -a partir del supuesto de que esta posee un estrato profundo, condición de las manifestaciones tradicionales de los pueblos- posibilitará descubrir su sentido interno, y cómo, en cuanto texto y música, cumple una función en la psiquis del niño.

Desde muy temprano, las canciones infantiles son parte de la colección de actividades del menor, cumpliendo diversos roles en su proceso de crecimiento (transmisión de normas y valores, colaboración en el desarrollo motor y de habilidades del lenguaje, etc.). Sin embargo, las canciones tradicionales infantiles -"unidades mínimas y simbólicas que expanden su significación en el imaginario colectivo"2- van más allá, cumpliendo un papel activo en la configuración de mundo a nivel consciente e inconsciente. Sus textos se anclan en emociones profundas y transculturales, aunque tratadas desde el sobrevenir cultural particular del medio que las genera y practica. Mediante breves metáforas el niño va interiorizando narraciones referidas a su propia cultura; mediante historias de personajes de la realeza o animales antropomórficos, el pequeño va incorporando el ideario de la sociedad que le es propia, e integra a su experiencia cuestiones que tienen que ver con temáticas inherentes a la vida, como el amor, la bondad y la maldad, la pérdida, la muerte; por medio de esta canción el niño introyecta símbolos y estructuras imaginarias que competen al ámbito inconsciente de su psiquis y que forman parte de un espacio compartido.

"El cancionero, en ese proceso de ritualidad primaria, aborda por vía de lo lúdico todos los hitos de la vida. Hay así canciones que, tras el juego de contar, sirven de ensayo y premonición al momento crucial de tener descendencia ('Inés, / ¿cuántos hijos vas a tener...?'). Otras que procuran resolver mediante el azar la elección de un estado ('soltera, casada, viuda, monja'), y otras que colocan a los niños ante la propia muerte, de manera explícita casi naif, como ocurre con el entierro de 'La niña del carabí', o de forma intuitiva y del todo inconsciente, como ocurre cuando las niñas cantan 'Al pasar la barca', ajenas, por supuesto, a la identidad del barquero (eterno Caronte) y a que su dinero es el pago por alcanzar la otra orilla de la Laguna Estigia”.

\footnotetext{
1 Sepúlveda 2013: 39.

2 Pelegrín 2001: 86-87.

3 Ruiz 2009: 77.
} 
El niño, en su condición de ente en estado de crecimiento y de permanente asimilación, va internalizando complejos ideológicos que se encuentran contenidos en los relatos inverosímiles de la tradición del folclore (que a su vez se anclan en antiguos mitos), que harán parte de sus cogniciones y, por tanto, de su modo de enfrentar e interpretar el mundo 4 . En esta línea, en última instancia es posible señalar que,

"consideramos al grupo infantil como una comunidad cultural específica, con sus propios cuentos, cantos y juegos, su forma animística de concebir el mundo, su estructura de pensamiento pre-lógico y mágico y, con una cultura oral-iniciática”.

Las narraciones infantiles tradicionales serían parte de la iniciación al mundo adulto por medio de la expresión de lo imaginario, constituyendo

"diseños cognitivos de argumentos existenciales, los cuales, quedarán en el inconsciente del niño como arquetipos culturales del comportamiento. La enculturación oral comporta el nivel más profundo de la cultura infantil y está expresada en forma de cuentos, canciones y juegos" 6 .

\section{LA MUERTE EN LA CANCIÓN INFANTIL TRADICIONAL CHILENA: APROXIMACIONES PARA SU ESTUDIO}

Desde la problemática del rol que poseen los cantos tradicionales en la configuración de mundo del pequeño, surgen las preguntas que configuran esta investigación: ¿Cómo es presentada la muerte en las canciones infantiles tradicionales del repertorio musical chileno? ¿De qué forma los textos aluden en forma simbólica a realidades más profundas? ¿Cómo se relacionan los textos con la música y cómo la música le otorga fuerza emocional y ritualidad a la enunciación del texto? ¿Qué función cumplirían en el desarrollo madurativo psíquico del niño? Para responder estas interrogantes, este trabajo se plantea como un estudio de tipo interdisciplinario, que faculte a una visión sistémica del caso.

En primer lugar, considera una aproximación desde la psicología que permita entender la función que cumplen, a nivel psicológico, las canciones en cuestión. Esta perspectiva nos es útil para aproximarnos al papel de estas como metáforas de un acontecer inaprehensible por la consciencia, y se ancla, en parte, en la propuesta de análisis de cuentos de hadas recogidos de la tradición oral realizada por el psicoanalista Bruno Bettelheim ${ }^{7}$. Su planteamiento dice relación con el hecho de que el cuento, debido a que alude a situaciones y a problemas existenciales ampliamente generalizados, sugiere en forma simbólica a la imaginación del niño modos de resolución de ciertos conflictos y el acceso en forma segura a dimensiones a las que no podría ingresar por sí solo. Plantea además que esta cualidad es propia del cuento tradicional y no así del cuento moderno. Para Bettelheim las historias actuales que se escriben para los niños por lo general evitan problemas existenciales, aunque estos resulten cruciales para su desarrollo:

"El niño necesita más que nadie que se le den sugerencias, en forma simbólica, de cómo debe tratar con dichas historias y avanzar sin peligro hacia la madurez. La historias

\footnotetext{
4 Peña Muñoz 1982: 4.

5 Herrero 1997: 168.

6 Herrero 1997: 168-169.

71995.
} 
'seguras' no mencionan ni la muerte ni el envejecimiento, límites de nuestra existencia, ni el deseo de la vida eterna. Mientras que, por el contrario, los cuentos de hadas enfrentan debidamente al niño con los conflictos humanos básicos" ${ }^{8}$.

Ahora bien, la canción tradicional, y en particular el romance, puede ser visualizado como un fenómeno análogo al cuento de hadas por constituir una narración donde se verifican representaciones simbólicas de la misma índole. Esto, no obstante, de un modo mucho más conciso, condensado poéticamente ${ }^{9}$ y cargado de la fuerza afectiva que le otorga la música y del carácter ritual favorecido por la repetición incesante que permite el canto.

Como ampliación de este planteamiento y como forma de acceder a un nivel psicológico más profundo, nos resultarán también convenientes los aportes de Carl Gustav Jung y su hipótesis acerca de la existencia de lo Inconsciente Colectivo (sustrato profundo de la psique, que no procede de la experiencia personal, compartido y poseedor de un carácter arcaico-mitológico) y de los arquetipos (contenidos de lo Inconsciente Colectivo, que adoptan manifestaciones simbólicas como el mito y el cuento popular, para así poder ser aprehendidos por la consciencia) ${ }^{10}$.

En segundo lugar, nuestro estudio considera una visión estético-antropológica que permita comprender el universo simbólico de estas canciones y encontrar el sentido que estas poseen. Partimos del supuesto que la existencia de expresiones tradicionales orales, como cuentos, mitos, leyendas y canciones, asoman, así como el mundo onírico, en cuanto símbolo de una verdad vasta y profunda. La lectura metafórica la realizamos, en mayor grado, a la luz de los planteamientos realizados por el filósofo y teólogo Jean Chevalier (quien dedicó gran parte de su obra al estudio del simbolismo de mitos, sueños, gestos, formas, colores y números encontrados en la mitología y el folclore), por el crítico de arte, mitólogo e iconógrafo Juan Eduardo Cirlot (realizador de importantes investigaciones en el área de la simbólica y hermenéutica, especialmente del medievo) y por el antropólogo, mitólogo e iconólogo Gilbert Durand (quien propone un tipo de hermenéutica que aborda las representaciones simbólicas de fuerzas motrices psíquicas que son comunes al ser humano, y a la que denomina como arquetipología). Por último, consideramos también la lectura de otras manifestaciones poético-folclóricas, de modo de establecer relaciones intertextuales, especialmente entre las canciones escogidas y los cuentos infantiles tradicionales. Para esta tarea es referente obligado el texto de Fidel Sepúlveda, El cuento tradicional chileno. Estudio estético y antropológico. Antología esencial (2013). El análisis de los símbolos presentes en cuentos recogidos del folclore, complejos en su construcción narrativa, nos da las pistas de cómo abordar los romances en cuestión.

Por último, este estudio considera una perspectiva semiótico-musical que permita comprender la relación entre el texto y la música, y cómo esta última forma parte de la simbolización. Esta perspectiva nos concede referirnos al modo de utilización de los elementos musicales y a cómo la organización y elección de estos son partícipes del sentido de las canciones estudiadas, en vinculación con la construcción cultural. El análisis intertextual de los aspectos musicales, nuevamente, es provechoso. De esta forma, nos resultan útiles algunos planteamientos de Philip Tagg, para quien juega un rol fundamental el sentido que construye la musicalidad de una obra en el receptor, dado mediante asociaciones y

8 Bettelheim 1995: 14.

9 La brevedad del romance infantil es una característica esencial de este tipo de manifestación. El último estadio por el que pasa el romance en la tradición oral es el infantil, constituyendo un refugio de este género y llevando al máximo la condensación de sus textos.

10 Jung 2010. 
reconocimientos de otros contextos que convergen en ella. De este modo, la música constituye un conjunto de discursos que se cruzan, uniendo sonidos, imágenes, recuerdos, sensaciones y deseos que son provocados en el receptor en relación con su imaginario histórico-social-cultural ${ }^{11}$. En este caso, entonces, la descripción analítico-musical apunta a descubrir ciertos vínculos entre el material musical y ciertas "correlaciones expresivas que ha construido una cultura alrededor de la música"12.

En cuanto al objeto de estudio mismo, para llevar a cabo la investigación se revisaron recopilaciones de canciones infantiles pertenecientes al repertorio tradicional chileno. Las fuentes utilizadas fueron la antología de Julio Vicuña Cifuentes, Romances populares y vulgares (1912), la de Ramón Laval, Contribución al folklore de Carahue (1916), la publicación Música folklórica infantil chilena, de Juan Pérez Ortega (1980), y los textos de Oreste Plath Folklore chileno: aspectos populares infantiles (1946) y Los juegos en Chile. Aproximación históricafolclórica (2014). También enriquecieron el estudio los escritos de Raquel Barros y Manuel Danemann, El romancero chileno (1970), y de Manuel Peña Muñoz, Juguemos al hilo de oro. Folclor infantil chileno (1999). Luego, fueron seleccionadas diez canciones, en sus distintas versiones en cuanto a texto se refiere, que aluden a la muerte como tópico protagonista. Todas ellas corresponden a romances, pues fue en estos donde encontramos en mayor medida la presencia de la muerte. Las canciones escogidas fueron Mambrú se fue a la guerra, El señor don Gato, Alicia va en el coche, En el jardín del cielo, Delgadina, Dónde vas Alfonso XII, Eran tres alpinos, La santa Catalina, Tengo una muñeca y El reconocimiento del marido.

En la mayoría de estas el relato se refiere a la muerte de algún personaje y a las circunstancias que le rodean. En Mambrú este muere en la guerra y es llevado a enterrar. En El señor don Gato el personaje central cae del tejado, se lastima, muere, e igualmente es llevado a enterrar. Las versiones más extensas de Alicia va en el coche incluyen hacia sus estrofas finales la revelación que la niña va muerta en dicho coche camino a encontrarse con su padre. En el breve romance En el jardín del cielo se menciona la realidad celestial de tres jóvenes mujeres, que una vez muertas, habitan este jardín supraterreno. Delgadina es la hija más virtuosa del rey, quien al negarse a acceder a los deseos de su padre, es encerrada y dejada morir de hambre y sed. En Dónde, vas Alfonso XII este último busca a Mercedes, posiblemente su esposa, mas esta ha muerto y, una vez más, es llevada a enterrar. La historia contenida en Eran tres alpinos incluye la muerte del menor de los alpinos, quien, por pretender a la hija del rey, es muerto por disposición del monarca, la muerte de la princesa, quien muere de pena por lo sucedido al alpino, y el deceso del mismo rey producto del desconsuelo generado por la muerte de su hija. La santa Catalina muere en manos de su padre pagano por ser descubierta en oración cristiana. En Tengo una muñeca esta última enferma, recuperándose en algunas versiones, no obstante muriendo en otras a pesar de los cuidados médicos recibidos. Por último, en El reconocimiento del marido, una mujer se entera de la muerte de su marido luego de preguntar a un soldado si es que lo conoce o lo ha visto.

Metodológicamente el estudio supuso una revisión exhaustiva de literatura referida a la música infantil en términos generales, de literatura alusiva al folclore musical infantil hispanoamericano y chileno en particular, de literatura concerniente a productos culturales infantiles pertenecientes a la tradición oral, y de literatura referida a la temática de muerte e infancia. Asimismo, conllevó la revisión de material pertinente con el enfoque teórico descrito anteriormente proveniente de la psicología, la antropología, la estética y la musicología. Luego fue posible reflexionar del tema en cuestión, analizar las canciones cuya temática es la muerte, y proponer una teoría respecto de cómo es tratado dicho tema

11 Tagg 1982.

12 Hernández 2012: 52. 
en el repertorio estudiado, por qué es tratado de la manera en la que se encuentra, cuál es el sustrato simbólico y qué función cumple en el desarrollo psíquico del niño y en la transmisión de contenidos arquetípicos.

\section{UNIVERSO SIMBÓLICO DE LOS ROMANCES INFANTILES CON TEMÁTICA DE MUERTE}

La noción de la vida después de la muerte se encuentra en la mayoría de las canciones estudiadas. De esta forma, la existencia es representada como el continuo entre un estado material y otro espiritual. Este hecho es concordante con el pensamiento del niño, para quien la muerte no constituye la desaparición perpetua del individuo. El niño pequeño concibe la muerte como un fenómeno temporal o reversible, plasmado de atribuciones mágicas, sin comprender su universalidad e inevitabilidad. Si se han relacionado con alguna persona que ha muerto, pueden perpetuar dicha relación por medio de rezos, cartas e incluso conversaciones con el fallecido, quien se encuentra "en el cielo". A medida que el niño crece, la muerte puede llegar a interpretarse como un castigo y si bien los niños logran identificarla como un hecho irreversible, aun no como uno universal. Recién alrededor de los nueve años el menor adquiere una idea de muerte culturalmente más estandarizada, emergiendo la noción de universalidad e irrevocabilidad, no obstante aún incomprensible su dimensión permanente y absoluta ${ }^{13}$.

Debemos destacar que si bien el tema de la muerte es un tópico de cierta recurrencia en el repertorio tradicional, no lo es en el repertorio infantil moderno. Al parecer la canción infantil "moderna" ha optado por brindar al niño un mundo donde suele no aparecer el dolor, escasamente la pérdida, privilegiando otras temáticas. Como señaláramos anteriormente, comentando a Bettelheim, en el caso de los cuentos ocurre algo similar. En la actualidad se han privilegiado narraciones donde se evitan temas considerados poco adecuados para el menor, como el de la muerte. Esto, porque "actualmente muchos adultos tienden a tomar al pie de la letra lo que se dice en los cuentos, mientras que debe considerarse como representaciones simbólicas de experiencias decisivas en la vida"14. Es precisamente esto último lo que también ocurriría en el ámbito de los cantos infantiles. Efectivamente, en los romances estudiados, la vida después de la muerte es expresada en forma explícita, simbólica o bien de ambas maneras. Luego será la interpretación de las imágenes simbólicas que rodean a la acción lo que nos permitirá comprender el contenido profundo de la narración.

Dentro de estas imágenes, la presencia de números es fundamental. Durand señala que "resulta notable que todos los mitólogos e historiadores de las religiones lleguen a consideraciones aritmológicas" ${ }^{15}$. Esta presencia es transversal a las narraciones folclóricas de diversa índole: son tres hermanos, y el más pequeño el más noble; la princesa (y todo su reino) dormirá por cien años antes de ser despertada; son siete los enanos, etc. Luego, "en el sistema simbolista los números no son expresiones meramente cuantitativas, son ideasfuerza, con una caracterización específica para cada uno de ellos"16, de ahí la relevancia de explicitar sus significados.

13 Rojas 2005; Zañartu, Krämer y Wietstruck 2008. Entender esta evolución nos servirá para comprender algunos hechos de las canciones a estudiar.

14 Bettelheim 1995: 187.

15 Durand 2006: 296.

16 Cirlot 1992: 328. 
El número tres es uno de los que ostenta mayor presencia, tanto en los cuentos tradicionales como en los romances. Tres hadas, tres hermanos, tres hijas, tres noches, tres intentos, etcétera.

"Tres hijas tenía un rey" (Delgadina $)^{17}$.

"Eran tres alpinos que venían de la guerra" (Eran tres alpinos) ${ }^{18}$.

Tres, número perfecto, expresión de orden en Dios, en el cosmos o en el ser humano, es símbolo de la totalidad divina para cristianos e hindúes ${ }^{19}$. Simboliza también la continuidad de la vida, el paso de una existencia material a una espiritual.

"Y encima de la caja / tres pajaritos van" (Mambrú se fue a la guerra $)^{20}$.

"Arriba de la tapa / carolín / tres pajaritos van" (Alicia va en el coche $)^{21}$.

Tanto en Alicia como en Mambrú los tres pajaritos parecen simbolizar la unión entre la tierra y el cielo, por tanto, el paso de una condición terrestre a una celestial. En concordancia con esto, Durand ${ }^{22}$ se refiere al número tres como tríada, como divinidad plural. Esta imagen se ve complementada por la referencia a los tres momentos del día, aurora, mediodía y crepúsculo, comienzo, medio y fin de todas las cosas, idea de completitud divina. El texto de estos romances, por tanto, metaforiza, mediante el uso del tres, la muerte como un encuentro con lo divino, contrario a la idea de la muerte como fin y desaparición en la nada.

Tanto en Delgadina como en Eran tres alpinos, de los tres personajes mencionados, es el menor el más virtuoso. Esto, porque es en la medida que se completa el número tres que se alcanza la nobleza, bondad y excelsitud. Este hecho nuevamente es coincidente con el acaecido en leyendas y cuentos de la tradición. Solo por nombrar alguno, recordemos aquel recopilado por Yolando Pino y antologado por Sepúlveda ${ }^{23}$, El lobo salamar o cuerpo sin alma, en el que es el menor de tres hermanos el único que vence el desafío. Bettelheim ${ }^{24}$, por su parte, plantea que en estos cuentos en que se presentan tres hermanos y en los que el menor, el menos dotado, se transforma en el héroe, se involucran la proyección y la identificación. Todos los niños se sienten en alguna ocasión menos inteligentes, menos hábiles, inferiores en general, que sus hermanos mayores u otros referentes de mayor edad. Por tanto, se identifican con el pequeño que llegará a ser héroe del cuento, encontrando consuelo y esperanza en el futuro.

Son innumerables las referencias al número tres en los cuentos de hadas, y la tradición narrativa chilena no es la excepción. Entre estos podemos mencionar Las tres toronjas del mundo ${ }^{25}$, recopilado por Laval, en donde el encuentro de las tres frutas le vale al príncipe encontrar a su prometida. El "Mostro"26, recopilado por Montenegro, en el que los tres perritos del pastor se transforman en tres palomos que ascienden al cielo revelando su

17 Pérez Ortega 1980: 39.

18 Pérez Ortega 1980: 60.

19 Chevalier 1986.

20 Peña Muñoz 1999: 38.

21 Pérez Ortega 1980: 33.

22 2006: 297, 312.

23 2013: 217-221.

24 1995: 114-117.

25 Sepúlveda 2013: 103-106.

26 Montenegro 1983: 125-134. 
identidad de tres ángeles. Y Los tres soldadillos ${ }^{27}$, también recopilado por Montenegro, donde tres desertores se casan con tres princesas encantadas superando la prueba de perder y recuperar tres prendas mágicas.

Luego, el número tres, unido a la imagen del pájaro, refuerza la interpretación antes propuesta. Siendo el vuelo la característica esencial de las aves, Chevalier ${ }^{28}$ manifiesta que este es el que a ellas otorga el valor simbólico de la relación entre cielo y tierra. Por otra parte, el pájaro puede ser interpretado como mensaje proveniente del cielo o como la liviandad de la inmortalidad. El mismo Chevalier ${ }^{29}$ señala que en el taoísmo los inmortales asumen la figura de aves justamente para significar la ligereza, como un modo de liberación de la pesadez terrenal. Para los brahmana, en ocasiones "el ave es la figura del alma escapándose del cuerpo", lo que es concordante con la idea de que "aún más generalmente, las aves simbolizan los estados espirituales, los ángeles, los estados superiores del ser"30. Cirlot, por su parte, asegura que "todo ser alado es un símbolo de espiritualización”, agregando que "esta significación del pájaro como alma es muy frecuente en todos los folklores"31.

Lo que otorga al pájaro su condición simbólica son sus alas. El símbolo del ala, como medio necesario para el vuelo, se halla inexorablemente ligado al de la ascensión. Durand, citando a Mircea Eliade, señala que el chamán, al escalar al poste,

"extiende las manos como sus alas un pájaro (...) y una vez llegado a la cima exclama: 'Llegué al cielo, soy inmortal', señalando claramente, de ese modo, la preocupación fundamental de esta simbolización verticalizante, ante todo escala levantada contra el tiempo y la muerte" 32 .

El pájaro, de esta forma, trasciende su categoría de animal en una gran cantidad de tradiciones, atribuyéndosele cualidades morales, en virtud de su poder de vuelo. En la imaginería alquímica, señala Durand ${ }^{33}$, el fin del vuelo se vincula a su voluntad de trascendencia, por lo que el ave es signo de pureza y elevación espiritual, existiendo un isomorfismo entre pájaro y ángel.

En algunas versiones encontradas de La santa Catalina, son justamente los ángeles los que bajan y los que se llevan a la niña al Paraíso. Los ángeles representan aquellas fuerzas invisibles "que ascienden y descienden entre el origen y la manifestación" 34 , y que entonces son capaces de transportar el alma a los cielos. Para los niños, los ángeles personifican la manifestación perceptible, icónica o visible de lo divino; ángeles con los que, además, pueden sentirse identificados, en cuanto pureza e inocencia, y que pueden cumplir un rol protector en la noche oscura y en el día de la muerte.

En las versiones revisadas de $\mathrm{El}$ señor don Gato no aparece el número tres, no obstante son siete ratones los que van sobre la tapa del ataúd. Mas, el sentido que posee el número siete, en este caso, se vincula al del tres, en la medida que alude al término de un ciclo y al comienzo de otro, término de una vida y comienzo de una nueva.

27 Sepúlveda 2013: 186-189.

28 1986: 154.

29 1986: 154 .

30 Chevalier 1986: 154.

31 Cirlot 1992: 350.

32 2006: 132-133.

33 Durand 2006: 138.

34 Cirlot 1992: 68. 
"Aunque tiene siete vidas / las siete ha entregado. / Sobre la cajita iban, / siete ratones cantando" (El señor don Gato) ${ }^{35}$.

"Sobre la cajita iban siete ratones bailando" (El señor don Gato $)^{36}$.

Por otra parte, Chevalier ${ }^{37}$ ofrece una larga lista de asociaciones entre el número siete y la totalidad dinámica del tiempo y del espacio, recurrente en diferentes culturas y tradiciones. Indica, asimismo, renovación y perfección.

El término de un ciclo se observa, por ejemplo, en el uso simbólico que se hace del número siete en Delgadina y en El reconocimiento del marido:

"Cumplidos los siete días se ha asomado a una ventana" (Delgadina $)^{38}$.

"Pasados los siete días se han abierto las ventanas" (Delgadina) ${ }^{39}$.

"Hija mía desgraciada, / ya va para siete meses / que me haces ser mal casada" $(\text { Delgadina })^{40}$.

"Siete años lo esperaré / si los siete años no llega / pal monasterio me iré" (El reconocimiento del marido $)^{41}$.

"Lo que te encargo, señor / que veas a mi marido / que va para siete años / a que lo lloro perdido" (El reconocimiento del marido) ${ }^{42}$.

Bettelheim ${ }^{43}$ destaca que siete son los días de la semana, señalando que en los cuentos, muchas veces, el número siete representa el período semanal como símbolo de cada uno de los días de nuestra vida.

A los significados anteriormente señalados, Cirlot ${ }^{44}$ agrega que el siete, en algunas ocasiones, también es símbolo del dolor. Este significado se expresa en los siguientes versos:

"El rey ordenó entonces / que a su hija encerraran / bajo siete llaves grandes / y en pieza emparedada" (Delgadina) ${ }^{45}$.

"Don Gato con la alegría / se ha caído del tejado / se rompió siete costillas / y la puntita del rabo" (El señor don Gato $)^{46}$.

"Llamaron a los médicos, / médicos y cirujanos / mataron siete gallinas / y le dieron de aquel caldo" (El señor don Gato $)^{47}$.

Junto con los números tres y siete encontramos la periódica presencia del número cuatro. Dicha cifra aparece aludiendo a la cantidad de individuos que cargan al féretro en algunas versiones de Mambrú, Dónde vas, Alfonso XII y El señor don Gato.

35 Pérez Ortega 1980: 29.

36 Pérez Ortega 1980: 29.

37 1986: 941-947.

38 Vicuña Cifuentes 1912: 28.

39 Vicuña Cifuentes 1912: 29.

40 Vicuña Cifuentes 1912: 30.

41 Vicuña Cifuentes 1912: 46.

42 Vicuña Cifuentes 1912: 48.

43 1995: 93.

44 1992: 330.

45 Pérez Ortega 1980: 38.

46 Pérez Ortega 1980: 29.

47 Plath 1946: 224. 
"cuatro oficiales lo llevan / lo llevan por la mar" (Mambrú) $)^{48}$.

"La reina se desmaya / y se pone a llorar. / Entre cuatro pajes / la llevan a enterrar" (Mambrú) ${ }^{49}$.

"Merceditas ya se ha muerto / y la llevan a enterrar; / cuatro duques la llevaban por las calles de Madrid" (Dónde vas, Alfonso XII) ${ }^{50}$.

"Le llevaron a enterrar / al pobrecito don Gato / y le llevaron en hombros / cuatro gatos colorados" (El señor don Gato $)^{51}$.

En los tres romances, son cuatro personajes los que llevan el cuerpo muerto a enterrar. $\mathrm{Y}$ es porque el cuatro simboliza lo terreno, la totalidad de lo creado, del universo, pero una totalidad que es material, la totalidad de lo perecedero ${ }^{52}$. Es la totalidad de lo que se deja atrás.

La recurrencia de ciertos números, entonces, obedece a un conocimiento subterráneo de la realidad. El tres, el cuatro, el siete, son símbolos que cumplen un rol: el tres simboliza el cielo, el cuatro la tierra y el siete, suma de los anteriores, la complexión del universo en movimiento ${ }^{53}$.

Por otra parte, esta significación de la muerte como un proceso de transformación natural, de logro de la ligereza, de conexión con el cielo y con lo divino, significada especialmente por el número tres, se muestra también en la inclusión del cristal como material del que se encuentra hecho el féretro. Chevalier ${ }^{54}$ señala que el cristal es símbolo de limpieza y de pureza. Cirlot, por su parte, plantea que el cristal “(...) es un símbolo del espíritu y del intelecto a él asociado (...)", agregando que "el 'estado de transparencia' se define como una de las más efectivas y bellas conjunciones de contrarios: la materia 'existe', pero es como si no existiera, pues que se puede ver a su través. No hay dureza a la contemplación, no hay resistencia ni dolor" $" 55$. La transparencia del cristal en la caja de reposo de Blancanieves, permite al príncipe y a los siete enanos contemplar la belleza incólume de la joven, dando paso a la acción remedial del pasajero estado de muerte, lo que comparten los romances estudiados:

"En caja de terciopelo / con tapa de cristal" (Mambrú) $)^{56}$.

"el cajón era de oro / y la tumba de cristal" (Mambrú $)^{57}$.

Vinculado al cristal se encuentra el oro, considerado desde tiempos ancestrales el material más precioso y perfecto: "tiene el brillo de la luz; el oro, según se dice en la India, es la luz mineral. Tiene carácter ígneo, solar y real, incluso divino" 58 .

El oro se liga en diversas tradiciones al sol, es imagen de su luz y de toda su connotación divina ${ }^{59}$. Y a su vez, se vincula a lo duradero e imperecedero: "el oro, dicen los Brahamana, es la inmortalidad. De ahí procede otro literalismo: tanto en China como en la India se han

48 Pérez Ortega 1980: 24.

49 Vicuña Cifuentes 1912: 150.

50 Pérez Ortega 1980: 45.

51 Plath 1946: 224.

52 Chevalier 1986: 380 .

53 Chevalier 1986: 942.

54 1986: 358.

55 1992: 152

56 Pérez Ortega 1980: 19.

57 Pérez Ortega 1980: 24.

58 Chevalier 1986: 784.

59 Chevalier 1986: 784; Cirlot 1992: 344. 
preparado drogas de inmortalidad a base de oro" ${ }^{60}$. Se refiere a la inmortalidad terrena, ya que el oro es a su vez símbolo del conocimiento; alcanzando el conocimiento, entonces, se logra la inmortalidad ${ }^{61}$.

"el cajón era de oro / y la tumba de cristal" (Mambrú) ${ }^{62}$.

"porque Mercedes ha muerto / y la llevan a enterrar (...) / con zapatos de oro y plata, / y claveles más de mil" (Dónde vas, Alfonso XII) ${ }^{63}$.

"a Delgadina darle agua / (...) unos con jarro de oro, otros con jarro de plata" $(\text { Delgadina })^{64}$.

"Estaba el señor don Gato / en silla de oro sentado; / calzando medias de seda / y zapatito dorado" (El señor don Gato) ${ }^{65}$.

La plata, así como el oro, es otra de las imágenes que suele aparecer en narraciones orales. Es así como en algunas versiones de Delgadina se alude a este metal. Simbólicamente,

"en el sistema de correspondencia de los metales y de los planetas, la plata está en relación con la luna. Pertenece al esquema o cadena simbólicos luna-agua-principio femenino. Tradicionalmente, en efecto, por oposición al oro, que es principio activo, masculino, solar, celeste, la plata es principio pasivo femenino, lunar, acuático"66.

La plata es símbolo de purificación, por su condición de blancura y luminosidad. Dice Delgadina:

"Tres hijas tenía el rey, / más hermosas que la plata" (Delgadina $)^{67}$.

"Un rey tenía tres hijas / bonitas como la plata" (Delgadina) ${ }^{68}$.

Por otra parte, tanto en algunas versiones de La santa Catalina como en El reconocimiento del marido, la muerte es propinada por un arma cortante. Y la función general de los elementos cortantes es, según Chevalier ${ }^{69}$, modificar la materia pasiva. Las armas cortantes mencionadas en las distintas versiones de ambos romances son el cuchillo o puñal, el hacha y la espada. El cuchillo es considerado por lo general el instrumento fundamental de los sacrificios, como el cuchillo de Abraham para el sacrificio de Isaac, así como también tendría el poder de alejar las influencias malignas ${ }^{70}$.

"Que traigan mi cuchillo / y mi puñal mejor" (La santa Catalina $)^{71}$.

"Traedme mi cuchillo, / para bon, bon, bon, / mi hacha y mi puñal" (La santa (atalina) $)^{72}$.

60 Chevalier 1986: 784.

61 Cirlot 1992: 344.

62 Pérez Ortega 1980: 24.

63 Pérez Ortega 1980: 45.

64 Vicuña Cifuentes 1912: 32.

65 Plath 1946: 223.

66 Chevalier 1986: 842.

67 Pérez Ortega 1980: 39.

68 Vicuña Cifuentes 1912: 29.

69 1986: 385.

70 Chevalier 1986: 385.

71 Pérez Ortega 1980: 17.

72 Plath 1946: 216. 
"en la punta de sus armas / firma las armas del rey, / y en el pomo de su espada / firma un aragonés" (El reconocimiento del marido) ${ }^{73}$.

El puñal-cuchillo estaría "asociado a las ideas de venganza y muerte, pero también de sacrificio" 74 . La muerte propinada por un arma tal, permite la liberación de la condición material, el alejamiento del mal y el sacrificio que ambos fines requieren y significan. El hacha, por su parte, coincide simbólicamente por cuanto "abre y penetra la tierra: es decir, figura su unión con el cielo, su fecundación. Hiende la corteza del árbol: es símbolo de penetración espiritual (hasta el corazón del misterio), así como instrumento de liberación"75.

En la búsqueda de otras imágenes de contenido simbólico, encontramos que en algunos de los romances revisados, los personajes corresponden a figuras de la realeza, como en $L a$ santa Catalina, Delgadina y Los Tres Alpinos. Según señala Cirlot,

"el rey simboliza, en lo más abstracto y general, el hombre universal y arquetípico. Como tal, posee poderes mágicos y sobrenaturales, según la creencia animista y astrobiológica, desde la India a Irlanda. Expresa también el principio reinante o rector, la suprema conciencia, la virtud del juicio y del autodominio"76.

Por otra parte, Chevalier añade que:

"el rey se concibe también como una proyección del yo superior, un ideal a realizar. Ya no tiene entonces ninguna significación histórica ni cósmica; se convierte en un valor ético y psicológico. Su imagen concentra en ella los deseos de autonomía, de gobierno de sí mismo, de conocimiento integral, de conciencia. En este sentido, el rey es, con el héroe, el santo, el padre y el sabio, el arquetipo de la perfección humana y moviliza todas las energías espirituales para realizarse. Pero esta imagen puede pervertirse en la de un tirano, expresión de una voluntad de poder mal controlada"77.

De esta condición ambivalente señalada por Chevalier se desprende la explicación de ciertos sucesos acaecidos en relatos como La santa Catalina y Delgadina. Efectivamente la figura masculina del rey es factible que aparezca ejerciendo un dominio abusivo, sin autoridad moral que lo respalde ${ }^{78}$. Luego, en la gran mayoría de las ocasiones, este rey también desempeña el rol de padre, el que puede llegar a constituirse en:

"símbolo de la posesión, del dominio y del valor. En este sentido, es una figura inhibidora; castradora, en términos del psicoanálisis. Es la representación de toda figura de autoridad: jefe, patrón, profesor, protector, dios. El papel paternal se concibe como que desalienta los esfuerzos de emancipación y ejerce una influencia que priva, limita, molesta, esteriliza y mantiene en la dependencia. Representa la conciencia frente a las pulsiones instintivas, los arrebatos o lo inconsciente; es el mundo de la autoridad tradicional frente a las nuevas fuerzas de cambio"79.

73 Vicuña Cifuentes 1912: 50.

74 Cirlot 1992: 159.

75 Chevalier 1986: 548-549.

76 Cirlot 1992: 386.

77 Chevalier 1986: 883-884.

78 Sepúlveda 2013: 53.

79 Chevalier 1986: 793. 
Lo planteado por Chevalier permite comprender lo ocurrido en La santa Catalina. En dicho romance el padre moro (figura de autoridad masculina), frente a la emancipación de la hija cristiana (figura femenina practicante de otro credo aprendido de otra figura femenina, su madre o su cuidadora, según la versión), coarta la posibilidad de emancipación de la niña, castigándola e infringiéndole la muerte. Algo similar ocurre en Delgadina. En este romance el padre encierra a su hija, prohibiendo que esta reciba agua o alimento. En ambos romances las hijas se encuentran bajo el dominio de un padre "malo", quienes son castigadas producto de la emancipación y desobediencia. En Delgadina, en particular, se muestra cómo, no solo la hija, sino que todos los habitantes del reino están bajo la obediencia del monarca, a pesar de su reprochable actuar.

El heroísmo es la virtud espiritual del hijo y el dominio es propio del padre ${ }^{80}$. Es por esta razón que la imagen paterna "representa el mundo de los mandamientos y prohibiciones morales, que pone obstáculos a la instintividad y a la subversión" 81 .

Si nos detenemos en el hecho de que la hija se vuelve prisionera de su padre, y ampliamos el nivel de análisis hacia uno de corte jungiano, es posible plantear que:

"ella representa lo inconsciente individual que, sin experiencia propia, no llega a emerger de lo inconsciente colectivo, su padre, que la abruma con todo su pasado. Pero el príncipe encantado, o el principio activo de la conciencia, viene a despertarla y liberarla del peso de tal sujeción; a cambio, ella le trae un fragmento de la memoria del mundo y, sobre esta base, puede progresar la acción conjugada del príncipe encantado y la hija del rey, que simboliza la alianza de lo inconsciente colectivo (el viejo rey), de lo inconsciente individual (la hija del rey), y de lo consciente (el príncipe)" 82 .

Los números, la presencia de aves, del cristal, del oro, de la plata, del puñal, del hacha, y de arquetipos humanos representados en la figura de reyes, príncipes y princesas, sitúan a la muerte en un espacio más cercano a una concepción premoderna que actual, desvistiéndola de su halo trágico, devolviéndole su condición de naturalidad y su función en el proceso de conexión con una realidad espiritual. De alguna manera, podría decirse que mientras el lenguaje del romance es moderno, su sustrato es ancestral.

La lectura metafórica de las canciones nos ha llevado a ampliar la mirada respecto del relato explícito, y a ver cómo los romances estudiados tratan acerca de cuestiones trascendentales referidas a la muerte, a la vida, y a la organización de la psiquis.

Evidentemente no podemos olvidar que muchas canciones, así como cuentos, se relacionan con la transmisión explícita de valores y pautas propias de la cultura, enlazándose con la tesis de que las canciones infantiles forman parte de los entrenamientos para posteriores desarrollos sociales ${ }^{83}$. Y es evidente también que muchas de las historias narradas en los romances en cuestión se vinculan a procesos históricos e integran el acontecer de un contexto dado, como por ejemplo ¿Dónde vas, Alfonso XII? y Mambrú se fue a la guerra ${ }^{84}$. Sin embargo, más allá de estos hechos, las imágenes simbólicas en repetición cargan un conocimiento ancestral compartido por la cultura, que es más profundo que el acontecer de la acción narrada, aportando a la construcción de la psiquis mediante la adquisición de este conocimiento.

80 Cirlot 1992: 347.

81 Cirlot 1992: 347.

82 Chevalier 1986: 569.

83 López 1990: 198.

84 Plath 2014: 80-82, 89. 
Por último, no podemos dejar de reflexionar respecto de cómo el desprecio de la imagen simbólica como fuente de conocimiento por parte de la ciencia y el proyecto de la modernidad, llevó a la merma de un saber propio de los pueblos antiguos y a una desconexión del hombre occidental actual con una dimensión trascendental del ser. Esto conlleva la pérdida de un conocimiento más cabal de la realidad, porque justamente, a partir del imaginario simbólico, el ser humano elabora su interpretación del mundo, organiza su cultura y genera conocimiento ${ }^{85}$.

\section{APROXIMACIÓN SEMIÓTICO-MUSICAL AL TÓPICO DE LA MUERTE EN LOS ROMANCES INFANTILES}

Para comenzar, es preciso señalar que partimos del supuesto que la música forma parte de la construcción de los individuos y de la creación de la realidad, siendo activa en la satisfacción de necesidades de pertenencia, identidad, comunicación, así como en el modo de gestionar las emociones ${ }^{86}$. En el caso de los niños, este hecho resulta fundamental, ya que estos se comunican privilegiando todo el lenguaje no verbal y simbólico, dibujando, pintando, jugando, teatralizando, cantando.

Las canciones infantiles no se pueden comprender solo en su instancia literaria, sino que es necesaria la consideración sine qua non de la melodía y el ritmo con que se entonan, del tipo de juego y el gesto que acompañan ${ }^{87}$. Es por esta razón que en esta sección realizaremos algunas consideraciones al respecto.

Para comenzar, haremos una muy breve descripción de los elementos musicales compartidos por los romances revisados ${ }^{88}$. En términos formales, podemos decir que se trata de canciones estróficas, con ausencia de estribillo. Las repeticiones que se pueden observar en algunos casos resultan de agregados o "muletillas" sin sentido semántico que han añadido los niños y que se han perpetuado en el tiempo, como esos chirivín chirivín chin chin o carolín cacaco leo lao que actúan como refranes recurrentes. Este hecho también es parte del juego o baile. En términos fraseológicos, nos encontramos con frases regulares, de comienzo mayoritariamente anacrúsico. Melódicamente, los romances estudiados privilegian el movimiento gradual. En la mayoría, el ámbito suele no superar la octava. Todos los romances revisados se encuentran en modo mayor (como la gran mayoría de las canciones infantiles folclóricas) y son armónicamente sencillos, privilegiando las implícitas funciones de tónica y dominante. En cuanto a la relación texto-música, todos son cantos silábicos. Se observa una predominancia de compases binarios (siendo una excepción el compás ternario en Dónde vas, Alfonso XII y en El señor don Gato). Los niños suelen cantar estos romances en un tempo allegro o allegretto, sin cambios agógicos. Se debe tener en cuenta que tempo y ritmo se vinculan necesariamente al juego o al baile, por tanto, deben ser adecuados a ellos. Los niños, ritualmente, "cantan los romances a la vez que juegan, de ahí que sean necesarios el ritmo y la repetición (...)" 89 .

Muchos de estos romances, entonces, no solo se cantan, sino que se bailan en ronda, llevando aparejado un tipo de canto responsorial. A modo de ejemplo, Plath señala que en la Santa Catalina:

85 Herrero Gil 2008; Solares Altamirano 2011.

86 Hernández 2012.

87 Ruiz 2009.

88 Para llevar a cabo esta tarea se revisaron las transcripciones que forman parte de la ya ampliamente citada publicación de Juan Pérez Ortega, Música folklórica infantil chilena (1980).

89 Moreno 1998: 84. 
"varias niñas sujetas de las manos forman un corro y dan vueltas alrededor de una de ellas que permanece arrodillada hasta que elige a una de las del círculo mediante esta fórmula: Cojo esta por linda y hermosa, / que es una rosa / acabadita de nacer. Entonces la elegida pasa a desempeñar el papel de Catalina" 90 .

Luego, la música trasciende lo meramente sonoro, incorporando, igual que antaño, manifestaciones afines a la danza como es la ronda, práctica simbólica presente en la tradición de una gran diversidad de pueblos ${ }^{91}$.

Los gestos y movimientos que acompañan a estos cantos, sumados a la continua repetición, nos ubican en un ámbito de ritualidad fascinante, una especie de trance que permite a sus ejecutores abrir su psiquis a otro nivel de conciencia y, por tanto, a una experiencia totalizante y placentera.

Avanzando un poco más allá, y retornando a la temática de la muerte, sin duda lo que primero llama la atención de las canciones infantiles en cuestión, en lo tocante al aspecto sonoro-musical, es la ausencia de un carácter trágico, comúnmente asociado a lo fúnebre en el ámbito occidental. Si al carácter desfatalizado de las canciones le sumamos el hecho de que algunas de ellas corresponden a canciones de corro, entonces más lejos parece encontrarse el sentir funesto de la muerte. Es en este punto donde nos detendremos, estableciendo un vínculo con la descripción musical antes hecha.

Partimos de la idea de que las sociedades sometidas a procesos históricos y culturales van otorgando significados a diversos aspectos musicales (que se transforman en unidades semántico-musicales), que si bien pueden mutar a lo largo del tiempo, poseen cierta estabilidad y permanencia. Ahora bien, la exposición del niño pequeño a una multiplicidad de estilos musicales está recién comenzando, y las relaciones entre determinados afectos o ideas, y las características sonoras y musicales de lo que escucha o canta no están aún plenamente instaladas.

Para poder aproximarnos a la relación que se ha dado entre música y texto u ocasión de muerte en nuestra sociedad y luego en particular al interior del repertorio tradicional infantil, nos servimos de la semiótica musical. Aunque sin referirse específicamente al repertorio infantil, los planteamientos de Philip Tagg, como señaláramos anteriormente, nos resultan muy útiles en la comprensión de la asociación entre música y temática de muerte. Tagg se ha preocupado de establecer correlaciones entre diversos componentes musicales y ciertas connotaciones afectivas. En su texto Musical meanings, classical and popular. The case of anguish, Tagg señala que se suele asociar el modo menor y el tempo lento, entre otros elementos más específicos, con campos semánticos ligados a la angustia, como lo fúnebre, lo fatal o lo melancólico ${ }^{92}$. Por otra parte, en 'Universal' music and the case of death Tagg plantea que en Occidente existiría la tendencia a asociar la muerte a manifestaciones musicales con

90 Plath 2014: 32.

91 Una hermosa interpretación al respecto es la que hace Juan Rodrigo Caro, poeta e historiador del siglo de oro español: "[Juan] Rodrigo Caro (1573-1647) dice que el simbolismo antiguo del juego era así: las tres primeras vueltas del corro, de izquierda a derecha, significaban el movimiento de los astros, o sea, su revolución de Oriente a Poniente, y las tres vueltas contrarias, el movimiento de los astros en esa misma dirección; las vueltas redondas, la perfección de la esfera; el niño en el centro, representaba el sol y, si había una niña, esta representaba la luna. Sacar del corro a uno de los niños daba a entender los cursos vacilantes de los planetas y todo el corro significaba las estrellas del firmamento, en armónico concierto. El canto simbolizaba el himno elevado a los dioses” (Plath 2014: 19-20).

92 Tagg 2004: 5. 
ciertas características específicas, cuestión que sin duda alguna no es transcultural, de ahí la diversidad de músicas relacionadas a este tema en distintas tradiciones ${ }^{93}$.

¿Qué características tiene la música fúnebre en nuestra cultura? El mismo Tagg en el recién mencionado texto de 1993 'Universal' music and the case of death se refiere a un pequeño experimento realizado en un simposio de comunicación transcultural, en el que constata que los participantes no tienen dificultad en afirmar que una música es fúnebre, triste o trágica cuando son sometidos a la audición incógnita de piezas de la tradición escrita que ciertamente poseen esta connotación (como el Lamento de Dido de la ópera Dido y Eneas de Purcell, o los primeros ocho compases del segundo movimiento, Marcha fúnebre, de la Sonata para piano $\mathrm{N}^{\circ} 2$ de Chopin, entre otros). Todas las piezas musicales señaladas por los auditores son tranquilas, lentas y en modo menor. Ninguna utiliza en forma recurrente notas cortas acentuadas, limitándose los saltos melódicos a la tercera mayor, siendo los intervalos más comunes tonos o semitonos. La línea melódica de casi todos los ejemplos consiste en breves y repetitivas frases y ninguno posee un ámbito mayor a una sexta menor ${ }^{94}$. En resumen, los elementos comunes encontrados en música fúnebre o ligada a la muerte en la cultura noroccidental europea son el modo menor, la tendencia a un volumen bajo, el tempo lento, el ámbito restringido, las frases repetitivas, la tesitura grave y el movimiento descendente.

Si nos detenemos por un momento en el discurso retórico de la música de los siglos XVII y XVIII, y en un amplio segmento de la música popular occidental actual, encontramos que la muerte es abordada desde un sentir trágico. Y dicha emoción ha sido expresada retóricamente en música acorde con lo referido por Tagg, mediante el modo menor, el tempo lento y el registro grave. Para Tagg, nuestra relación ritualizada con la muerte es triste, nostálgica, introvertida, discreta, inmóvil, calma, controlada, cuidadosa, prudente, pausada, oscura, pesada, monótona, inactiva. Y son estos los factores que hacen nuestra música fúnebre, fúnebre ${ }^{95}$.

Empero, las canciones infantiles con temática de muerte estudiadas no poseen los rasgos antes señalados. Estos no aparecen cuando se narra la llegada de la noticia de la muerte del amado o de la amada, ni cuando el padre encierra a su hija dejándola morir de hambre y sed, o bien cuando la mata con un cuchillo o puñal, ni cuando el rey asesina al pretendiente amado de su hija, ni cuando el gato cae del tejado; tampoco acompañan a las expresiones de dolor que en estas aparecen, como cuando los niños cantan qué dolor, qué dolor, qué pena.

Proponemos que la ausencia de elementos musicales asociados al sentir fatídico y desdichado -lo que, como veremos, se relaciona con el análisis simbólico realizado anteriormente-se explicaría básicamente de tres maneras. En primer lugar, los cantos aludidos se encuentran intrínsecamente ligados y casi subordinados al juego, por tanto su carácter musical debe favorecer y adaptarse a la actividad lúdica. En segundo lugar, el aprendizaje e internalización de la muerte no debiese por qué estar acompañada de un sino trágico, debido a la conceptualización de muerte que posee el niño. Si bien este experimenta angustia frente al temor de desaparición de figuras significativas, no será sino con el aprendizaje cultural occidental que la muerte adquirirá aquella connotación de desgracia e infortunio que nuestra sociedad le ha brindado. Para la psiquis del niño, repetimos, la muerte es temporal o reversible, y él no es capaz de comprender su universalidad, inevitabilidad e irrevocabilidad. De ahí que la angustia, la tristeza, el pesar, y en general los afectos surgidos

\footnotetext{
93 Tagg 1993: 1.

94 Tagg 1993: 5-9.

95 Tagg 1993: 9.
} 
en los adultos frente a la experiencia de la muerte, no son los mismos que se despiertan en el mundo infantil, lo que condicionaría de un modo distinto la relación música-contenido semántico. En tercera y última instancia, todo el universo de símbolos presentes en los romances aludidos, y que acompañan a la acción de la muerte, denotan el significado de esta última no como término y final, sino como momento de tránsito hacia un nuevo estado. Por tanto, la muerte no constituye el fin de la vida sino su transformación, por lo que no habría razón para lamentos.

Los hechos antes descritos explicarían la ausencia de diferencias musicales entre canciones infantiles que tratan del amor, el juego, la muerte o el incesto. Esto es fundamental, porque el niño incorpora estos temas con una misma carga emotiva. Luego, serán los discursos de los adultos construidos alrededor de estos temas los que marcan la diferencia, lo que será potenciado por la exposición a la televisión y el cine, en donde en un gran cúmulo de producciones sí se establece una correlación "adulta” entre contenido semántico, carga emotiva, imagen, música y sonidos.

Ante todo lo anteriormente dicho surge una interrogante crucial que radica en el hecho de que tanto las músicas como los textos de los romances estudiados no son de autoría infantil. Aunque quepa señalar que, de todas maneras, los niños hacen suyo el producto estético que devendrá canción infantil, la interrogante de cómo han sido generados poemas cantados sin relaciones evidentes entre texto y música de acuerdo con la cultura predominante, no resulta en modo alguno fácil de responder. Una posible hipótesis quizá la constituya el hecho de que estos cantos provengan de ámbitos culturales marginales respecto del proyecto moderno, el que cristalizó los aspectos semánticos de la música a partir de la discusión retórica característica del barroco. En cuanto parte del repertorio tradicional, los romances estudiados dan cuenta de un nivel de subjetividad no plenamente desarrollado, donde la contingencia emocional no tiene el tamaño que alcanzará con el avance de la modernidad. En este sentido, podría suponerse una relación de identidad entre la niñez y la psicología del ser humano premoderno.

\section{BREVE REFLEXIÓN FINAL}

El objetivo de este estudio ha sido mostrar cómo las canciones infantiles de tradición oral que incluyen la temática de la muerte, forman parte de un cúmulo de producciones culturales propias de los pueblos, y que, como tales, poseen un sustrato profundo. Para acceder a este nivel, fueron necesarias herramientas disciplinarias y epistemológicas provenientes de la psicología, la antropología y la estética.

En el caso del acervo infantil, y luego de las indagaciones realizadas, es posible hacer una síntesis interpretativa a distintos niveles de profundidad. En un nivel superficial, podemos entender acerca de lo que tratan las canciones desde lo que la narración expone explícitamente, a lo que podemos sumar la comprensión de procesos histórico-sociales en los que estas se anclan. Luego, la interpretación simbólica nos lleva a entender cómo estos romances surgen desde el niño, y lo enfrentan a conflictos propios de su existencia. En un último nivel, el de mayor profundidad, la interpretación nos conduce al descubrimiento de asuntos que traspasan la experiencia del niño como individuo, y que dicen relación con cuestiones referidas a arquetipos y simbolismos inconscientes compartidos por los seres humanos y moldeados a posteriori por el contexto cultural.

Es así como la presencia de la muerte en el romance infantil y los elementos que le rodean se explican, en gran parte, por la necesidad del niño de enfrentarse a sus pulsiones, angustias y conflictos "desde fuera", en la canción, en el canto, y así poder identificarse, manejar aquellos conflictos y darles forma. Y por la necesidad del ser humano de recuperar y 
expresar aquella perdida vinculación con su propia psiquis, su alma y la totalidad. La muerte es cambio, es trascendencia. Puede incluso significar alcanzar la unidad entre el cielo y la tierra, la espiritualización del ser y el logro de la levedad de la inmortalidad mediante la liberación de la pesadez terrenal. De alguna forma, estos cantos, así como cuentos y mitos, unen al ser humano actual con el ancestral, por una parte, y lo conectan con realidades psíquicas profundas, como el inconsciente individual y colectivo.

Luego, mediante el análisis musical, encontramos que la música de estos cantos es concordante con los significados profundos que estos cargan, sin poseer las características que comúnmente asociamos a la muerte en la modernidad occidental. El elemento semántico retórico, que es tan importante a partir del siglo XVIII, es desfavorecido frente a otros aspectos musicales más arcaicos como es por ejemplo la repetición, cuyo fin está relacionado a la integración de un contenido a niveles que traspasan la superficie de lo intelectual, operando a otro nivel de conciencia.

Por último, al vivenciar la experiencia del canto tradicional, la mente del niño incorpora estos contenidos, formando parte de su proceso de crecimiento y maduración. De ahí un factor más de la importancia que para nosotros constituye el hecho de sumergirse en un conocimiento más profundo de un producto cultural en extinción, contribuyendo al rescate de un repertorio chileno particular, instrumento de conservación de la memoria colectiva de una comunidad. Una lectura como la que se sugiere en este estudio, de este modo, se puede constituir en un testimonio de los valores, el modo de instalarse en el mundo y la percepción respecto del propio acontecer de un pueblo ${ }^{96}$.

\section{BIBLIOGRAFÍA}

Barros, RaQuel y Manuel Danemann

1970 El romancero chileno. Santiago: Ediciones de la Universidad de Chile.

Bettelheim, Bruno

1995 Psicoanálisis de los cuentos de hadas. Barcelona: Grijalbo Mondadori.

Chevalier, Jean

1986 Diccionario de los símbolos. Barcelona: Herder.

Cirlot, Juan Eduardo

1992 Diccionario de símbolos. Barcelona: Labor.

DURAND, GILBERT

2006 Las estructuras antropológicas de lo imaginario. Introducción a la arquetipología general. México: Fondo de Cultura Económica.

Hernández SALgar, Óscar

2012 "La semiótica musical como herramienta para el estudio social de la música", Cuadernos de música, artes visuales y artes escénicas, 7/1 (enero-junio), pp. 39-77.

Herrero, José Antonio Martín

1997 Manual de antropología de la música. Salamanca: Amaru Ediciones.

Herrero Gil, Marta

2008 "Introducción a las teorías del imaginario. Entre la ciencia y la mística", Revista de Ciencias de las Religiones 13, pp. 241-258.

96 Sepúlveda 2013. 
Jung, Carl Gustav

2010 Los arquetipos y lo inconsciente colectivo. Madrid: Editorial Trotta.

LAVAL, RAMÓN

1916 Contribución al folklore de Carahue. Madrid: Librería general de Victoriano Suárez.

LÓPEZ TAMÉS, RoMÁN

1990 Introducción a la literatura infantil. Universidad de Murcia.

López CANo, RuBÉN

2007 Semiótica, semiótica de la música y semiótica cognitivo-enactiva de la música. Notas para un manual de usuario. Texto didáctico (actualizadojunio 2007). [En línea]. Recuperado de www.dropbox. com/s/dj48ulqyl9jlyyh/Semiotica_Musica.pdf

Montenegro, ERnesto

1983 Mi tio Ventura. Cuentos populares de Chile. Santiago: Editorial Andrés Bello.

Moreno Verdulla, Antonio

1998 Literatura infantil: introducción en su problemática, su historia y su didáctica. Cádiz: Servicio de Publicaciones de la Universidad.

Pérez Ortega, Juan

1980 Música folklórica infantil chilena. Valparaíso: Ediciones Universitarias de Valparaíso.

Pelegrín, Ana

2001 "Romances del repertorio infantil en América”, Anales de Literatura Hispanoamericana, 30, pp. 69-95.

Peña Muñoz, Manuel

1982 Historia de la literatura infantil chilena. Santiago: Editorial Andrés Bello.

1999 Juguemos al hilo de oro. Folclor infantil chileno. Poesía. Santiago: Arrayán Editores.

Plath, Oreste

1946 Folklore chileno. Aspectos populares infantiles. Santiago: Prensas de la Universidad de Chile. (Tirada aparte de los Anales de la Universidad de Chile, Tercer y Cuarto semestre de 1945).

2014 Los juegos en Chile. Aproximación histórica-folclórica. Santiago: Fondo de Cultura Económica.

Rojas, PAMEla

2005 El niño y la muerte. [En línea]. Recuperado de http://medicinafamiliar.uc.cl/html/articulos/040.html

Ruiz, María Jesús

2009 "Repertorio tradicional infantil de Cádiz: texto, rito, gesto y símbolo", Revista OCNOS, 5 , pp. 69-86.

Sepúlveda Llanos, Fidel

2013 El cuento tradicional chileno. Estudio estético y antropológico. Antología esencial. Santiago: Ediciones Universidad Católica de Chile.

Solares Altamirano, Blanca

2011 "Gilbert Durand, imagen y símbolo o hacia un nuevo espíritu antropológico", Revista mexicana de ciencias políticas y sociales, 56/211 (abril), pp. 13-24.

TAgG, Philip

1982 "Analising popular music: theory, method and practice”, Popular Music, 2, pp. 37-65.

1993 'Universal' music and the case of death. [En línea]. Recuperado de www.academia.edu/5669564/ Universal_music_and_the_case_of_death_1993_

2004 Musical meanings, classical and popular. The case of anguish. [En línea]. Recuperado de www.academia.edu/5669462/Musical_meanings_classical_and_popular._The_case_of_anguish_2004_ 
Vicuña Cifuentes, Julio

1912 Romances populares y vulgares. Santiago: Imprenta Barcelona.

Zañartu, Cristián, Christiane Krämer, y María Angélica Wietstruck

2008 "La muerte y los niños", Revista Chilena de Pediatría, 79/4, pp. 393-397. 